\title{
Scenes and Social Movements
}

\author{
Darcy K. Leach and Sebastian Haunss
}

Charles Perry, in his history of San Francisco's Haight-Asbury district, describes a network of places, shops, newspapers, groups, events, and people that together constituted a kind of hothouse within which the hippie counterculture took root and flourished. In Perry's words,

A whole world now revolved around the Haight-Ashbury ... By September 1966 newcomers were showing up in the Haight almost daily. Neighborhood windows had blossomed with all sorts of decorations: curtains made of blankets or Indian print fabrics from the Psych Shop, wind chimes, little glass sculptures, or god's-eyes ...

[It] was the center of the Northern California psychedelic community. The Oracle was the world's only psychedelic newspaper, the Diggers were the only psychedelic political movement, and the Haight had more hippie business concerns than anyplace else. A new batch had just opened, including Annex 13 Books and a store selling bead stringers' supplies .... (Perry 2005)

This is the kind of social and spatial infrastructure that one often sees around more culturally oriented social movements. We call places like Haight-Ashbury a scene. In this chapter we elaborate a working definition of a scene, drawing distinctions between it and other free-space concepts. We then offer several propositions about the roles that scenes may play in social movements, and close with a few words about the future utility of the scenes concept.

Offe (1985) noted over two decades ago that social movements increasingly operate in a realm between the public and private spheres. They seek to "politicize the institutions of civil society ... and thereby to reconstitute a civil society that is no longer dependent upon ever more regulation, control, and intervention." They do this "through practices that belong to an intermediate sphere between 'private' pursuits and concerns, on the one side, and institutional, state-sanctioned modes of politics, on the other" (Offe 1985: 820, emphasis in original). Social movement researchers have long been aware of the social formations that make up this intermediate sphere, variously labeling them "free spaces" (Evans and Boyte 1992; Couto 1993; Polletta 1999b; Groch 2001; Futrell and Simi 2004; Johnston 2005), "submerged networks" (Melucci 1989; Mueller 1994). "oppositional subcultures" (Johnston 1991), "social movement communities" (Buechler 1990; Taylor and Whittier 1992, 1995; Taylor and Rupp 1993), "abeyance structures" (Taylor 1989; Taylor and Rupp 1993), "cultural 
Hirsch 1995) "safe spaces" (Gamson 1996; Hill-Collins 2000), "cultures of solidarity" (Fantasia 1988), and "movement halfway houses" (Morris 1986; Rupp and Taylor 1987). By whatever name, scholars have emphasized them as places where oppositional frames and collective identities are constructed. But even as the importance of these spaces has not been overlooked, we still know surprisingly little about their inner dynamics, the circumstances under which they arise, or their effect on social movement development.

In her review of this literature Polletta proposes a typology of three different kinds of free spaces: transmovement, indigenous, and prefigurative spaces. Transmovement spaces may be formal organizations or loose activist networks that serve a large population of activists in one or more movements by offering trainings and other resources to spur mobilization. The Highlander Folk School and the National Women's Party are examples of transmovement spaces. Such networks are characterized by extensive social ties, in which "activists are linked across a wide geographic area, have contacts in a variety of organizations and are often veterans of past movements" (Polletta 1999b:9). An indigenous space, her second type, is one that is "indigenous to a community and initially is not formally oppositional" (Polletta 1999b: 10). These are more isolated networks marked by dense social ties, and are not created by the movement but come to be used by it, such as Southern black churches in the civil rights movement. Lastly, prefigurative spaces are the explicitly oppositional spaces created by movements to enact their countercultural lifestyle in an attempt to prefigure their desired world. Though it depends on their ideology, these spaces are often characterized by symmetrical interactional ties based on egalitarian power relations. As we will show, scenes share all of the traits of prefigurative spaces, but they can also contain transmovement spaces and isolated networks of dense ties.

A weakness of many definitions of free spaces is that they tend to focus on their function rather than on identifiable characteristics. To give a few examples, free spaces have been defined as "physical space in which to communicate and share perceptions of [a group's] experiences" (Groch 2001: 65), or "small-scale settings ... where [activists] can nurture oppositional movement identities" (Futrell and Simi 2004: 16). For Polletta they are settings that "generate the cultural challenge that precedes or accompanies political mobilization" (1999b: 1), and Johnston (2005: 110) sees them as places "where intimate association foments collective identity, shared grievances, oppositional frames, and tactical innovation" Such functional definitions tend to breed tautological reasoning, stretching the idea of free spaces to the point where it includes any and all locations that contribute to mobilization. As a result, at least four important differences in the way free spaces are characterized have been obscured.

First, there are significant differences in terms of their structure and scope. Some scholars speak explicitly of these spaces as networks (Melucci 1989; Taylor and Whittier 1992, 1995; Taylor and Rupp 1993; Groch 2001; Futrell and Simi 2004), and others discuss only single spaces or leave the question of their number and relation to one another unexamined (Morris 1984; Rupp and
Taylor 1987; Taylor 1989; Evans and Boyte 1992; Couto 1993; Hill-Collins 2000). Some researchers focus on groups and organizations (Morris 1986: Rupp and Taylor 1987; Evans and Boyte 1992; Groch 2001). Others extend the concept to include traditional institutions of socialization, such as schools. families, friendships, parties, and the media (including cyberspace) (Fantasia and Hirsch 1995; Hill-Collins 2000; Futrell and Simi 2004). Some include periodic or one-time gatherings and events (Taylor and Whittier 1995; Futrell and Simi 2004) where others do not. Patricia Hill Collins (2000) includes the black women's blues tradition and the voices of black women writers as "safe spaces" that help to empower black women. Johnston (2005) goes even further, categorizing oppositional speech situations and "event seizures" that occur under oppressive authoritarian regimes (for example, episodes of chanting, singing, and intense cheering at soccer games) as temporary free spaces. Clearly, more refined distinctions among these various types are necessary if we are to better understand their effect on social movements.

Second, there are differences in how free spaces are presumed to be organized. Are they democratically or hierarchically structured? Evans and Boyte (1992) emphasize internal democracy as a necessary attribute of free spaces but others either see them as undemocratically organized or do not specify their governing structure (Rupp and Taylor 1987; Taylor 1989; Couto 1993; Groch 2001; Futrell and Simi 2004). Still others imply that free spaces must be democratic by choosing cases that are committed to participatory democracy (Melucci 1989; Taylor and Whittier 1992, 1995; Taylor and Rupp 1993), but without theorizing how their internal structure may affect mobilization.

Third, there are differing views regarding free spaces' role in cultivating the skills and values of citizenship in a representative democratic polity. Research on voluntary associations suggests that this depends not only on the degree to which the spaces themselves are democratically organized, but also on the kind of democratic structure (e.g., representative, direct, collectivist; see Fung 2003). While only a few scholars explicitly discuss this dimension (Morris 1986; Evans and Boyte 1992; Couto 1993), it seems clear that undemocratic or simply oligarchic free spaces (Rupp and Taylor 1987; Taylor 1989; Futrell and Simi 2004) would not cultivate democratic citizenship skills. Other research suggests that spaces organized in a more radically egalitarian manner (Melucci 1989; Taylor and Whittier 1992, 1995; Taylor and Rupp 1993) also may not foster the skills needed in a representative democracy because they reject the principle of representation in favor of non-hierarchical, consensus-based self-governance.

Fourth, there are differing views regarding whether free spaces are created by the movements or existed beforehand as mainstream organizations that catalyze mobilization. This is important because spaces already embedded in mainstream society will tend to afford a narrower range of latitude in the ways movements may use the spaces. Also, if we focus on these indigenous spaces, we are also likely to privilege their role as proto-movement organizations and their importance in the early stages of mobilization, whereas appropriated 
countercultural spaces are likely to be more important in the later phases of the movement, functioning primarily to create and preserve movement culture.

These four distinctions suggest that different kinds of social and cultural spaces are likely to affect movements' development, recruitment, and longevity, as well as their relations with other movements and with bystander publics, in different ways. In order to understand precisely the role of scenes in social movements, then, we need to more clearly distinguish them from the more commonly recognized free-space concepts.

\section{Scenes}

A good starting place is to identify the main dimensions on which scenes differ from free spaces as they are commonly understood in the literature. Based on our review, there are four common assumptions underlying discussions of free space. First, they are seen as places where group members are able to interact beyond the reach of oppressor group-affording a degree of autonomy and agency to participants. ${ }^{1}$ Second, they are treated as necessarily political and linked to social movements. ${ }^{2}$ Third, free spaces are almost always portrayed as having positive effects on social movements, functioning to facilitate rather than hinder mobilization. ${ }^{3}$ Fourth, they are frequently presumed to be attached only to politically liberal or left-leaning movements. ${ }^{4}$ of these four characteristics, the first is the only one that is usually made explicit and is probably true of all free spaces. The others are commonly assumed, but not always empirically warranted.

Other than the assumption of autonomy, none of these characteristics is necessarily true of scenes. Scenes are not necessarily political, and when they are political, their orientation is not necessarily left-leaning. Scenes are not necessarily attached to social movements, and even when they are, a scene

Ironically, the "free spaces" described by (Evans and Boyte 1992), who first coined the term, are the least free for oppressed groups, because they are characterized as necessarily public and open to all -. as pluralistic spaces in which people learn to articulate their interests (by debating those with other interests) and develop the civic skills necessary for participation in a representative democracy. This definition would seem to exclude separatist spaces where members of dominant groups are unwelcome as well as spaces used by countercultural groups who reject representative democracy.

2 Exceptions here are Couto (1993) and Polletta (1999b), who both allow that some free spaces develop prior to and independently of social movement mobilization, and may in that sense be pre-political. But it is still taken for granted that they will eventually become political, and their functions for non-political subcultures are not theorized.

3 Again, Polletta is the exception, noting that "With respect to free space analysts" claim that dense and isolated networks facilitate protest, it is just as likely that, depending on the circumstances, such networks may impede protest" (Polletta 1999b: 20).

4 Futrell and Simi (2004) are the sole exception we have found here. cannot be reduced to the movement itself or to the organizations within it And where scenes are connected to a movement, the relationship between the two is not always beneficial for the movement.

We define a scene as simultaneously a network of people who share a common identity and a common set of subcultural or countercultural beliefs, values, norms, and convictions as well as a network of physical spaces where members of that group are known to congregate. Put differently, it is a network of free spaces that encompasses one or more subcultures and/or countercultures. Where movement and scene are tightly interconnected, one may speak of a movement scene. Countercultural scenes are necessarily engaged in a political struggle in the sense that they actively oppose and want to change the dominant culture. Subcultural scenes are sometimes political and sometimes purely lifestyle oriented. 5 Based on the orientation of their core, then, we can identify three main types of scenes: subcultural non-movement scenes, subcultural movement scenes, and countercultural movement scenes. Any kind of subculture may develop a scene, but only some subcultures develop a political agenda, leading the scene to attach itself to a movement. For example. Irish expatriates living in Boston today would probably be classified as an apolitical subculture, whereas a century ago, that same social network would be better classified as a political subculture, formed in response to active repression. In both cases, there was a scene comprised of a network of clubs, pubs, and periodic gatherings that were more or less geographically concentrated (more then, less now) in certain parts of the city.

There are three characteristics of scenes we want to emphasize. First, a scene has its own culture. In addition to shared convictions, participants in a scene share distinctive dress codes, aesthetic tastes, social norms, linguistic patterns, signs and symbols, and specialized knowledge that set them apart. Yet. being part of a scene is more than just an expressive act or a question of style. Even though expressive forms play a central role, scenes cannot be reduced to "signcommunities" (Hebdige 1979). They are more an attempt at experimenting with a culture than they are an expression of it.

Second, the boundaries of scenes are constantly in flux. The transition between core members and those less integrally involved is fluid, as is the transition between members and non-members. Neither the boundaries of a scene nor its membership criteria can be determined from the outside

5 Until now, it is only the subcultural aspect of the scene as an alternative lifestyle that has garnered scholarly attention. In the only systematic study of scenes to date. Hitzler, Bucher, and Niederbacher (2001) analyze twelve different lifestyle groups in Germany, including among others "skaters," Turkish street gangs, "ravers," "freeclimbers," and young anti-fascists. They categorize seven of these lifestyle groups as scenes, using the following criteria: the participants shared a common and acquired knowledge, identified with the scene, acted in a value-oriented way, felt that engagement in the scene was important for their lives, and had their own meeting points, events, and internal media. 
because a scene is ultimately constituted through a face-to-face process of self-identification and mutual recognition. In establishing the boundaries of membership this process also marks social territory, lending distinction to scene members and differentiating them from other social groups. As informal structures with fluid boundaries, scenes are somewhat fragile entities. Membership is generally based on cultural markers that are not difficult to shed, making it relatively easy to leave a scene. In principle, one is free to come and go as they please, although the scene can exert substantial pressure on a person to either join or leave.

Third, perhaps the most distinctive feature of a scene is that it refers simultaneously to an integrated network of both people and specific locales. The geographic aspect of scenes is expressed in the fact that they form around recognized scene locations-meeting places like bars, clubs, parks, street corners, and so on, in recognized parts of town-where being part of the scene can be physically experienced and the signifiers of membership can be enacted and validated. Knowing the location of such places is often itself a badge of membership.

Studying scenes as rooted in physical space rather than merely being symbolic communities has three important implications: that understanding scenes requires a focus on concrete collective practices, not just the discursive meanings and frames conveyed by those practices; that those practices shape and are shaped by the physical spaces in which they occur; and that the presence of a scene suggests a physical struggle for control over territory. Indeed, the ability to determine how scene spaces will be used and by whom is often violently contested. This struggle may take place between factions of a subculture or competing subcultures within a non-movement scene; between a subculture and a counterculture within a movement scene; or between a movement scene and the police or a countermovement.

As social networks, scenes also share traits with Melucci's notion of "submerged networks" and with what Taylor and Whittier call "social movement communities." Melucci refers to submerged networks as "movement areas" that "take the form of networks composed of a multiplicity of groups that are dispersed, fragmented, and submerged in everyday life, and which act as cultural laboratories [for] the experimentation and practice of new cultural models, forms of relationships and alternative perceptions and meanings of the world" (Melucci 1989: 60). These social networks become visible when they become engaged in overt political conflict, but during phases of less obvious political activity, they operate as a latent movement infrastructure, under the radar of most non-participants. In a similar vein, Taylor and Whittier define social movement communities as "a network of individuals and groups loosely linked through an institutional base, multiple goals and actions, and a collective identity that affirms members' common interests in opposition to dominant groups" (Taylor and Whittier 1992: 107).
Movement scenes, submerged networks, and social movement communities all share a high degree of autonomy from dominant groups, all refer to networks of persons, groups, and places, and are all prefigurative spaces created in the movement's image rather than indigenous premobilization groups. Where they differ is that both of the other two concepts are seen as necessarily connected to and beneficial for social movements, and the concept of a scene more explicitly addresses the importance of physical space as it relates to social movement action. By investigating both the social and spatial aspects of scene networks and by distinguishing scenes analytically both from the movement itself and from the mainstream communities in which scenes are embedded, we hope to better capture the various relationships that may obtain between scenes and movements and the conditions that determine whether and how that relationship develops.

\section{The Scene in the German Autonomous Movement}

To elaborate how the scenes concept contributes to our understanding of movement behavior, we will draw some examples from the autonomous movement in Germany, focusing on the scenes in Berlin and Hamburg that have grown up around this movement over the last several decades. This analysis is based on our own experiences as activists in this movement between 1995 and 2005 and on extensive fieldwork conducted for separate projects, including a year of participant observation in an autonomous antinuclear group (2000-2001). the evaluation of movement newspapers over a period of thirteen years, as well as online sources, and other movement documents, and in-depth interviews with thirty-two movement participants in six Autonomen-style groups from various German cities.

The German autonomous movement developed out of remnant strands of the post 1968 New Left. Activists from Frankfurt's "Spontis" who rejected the parliamentary path of leading figures like Joschka Fischer and Daniel Cohn Bendit, and radicals in the antinuclear movement who did not want to reduce their political agenda to ecological issues were the first to call themselves "Autonome" (Geronimo 2002). Influenced by the Italian "autonomia operaia," they developed their oppositional politics around a militant anti-authoritarian subjectivism and opposition to what they perceived as the dogmatism of both the old and new left. As Katsiaficas (1997) has noted, however, in contrast to the Italian movement, where autonony was primarily seen as a form of workingclass organization, free from the control of trade unions and political parties, in the German context the term connotes a rejection of all forms of hierarchical organization. The Autonomen have been a continuous presence in the German left since the late 1970 s, playing a significant role in a range of movements and campaigns, from the antifascist, women's, and antiwar movements, to the current global justice movement. 
The politics of the Autonomen is often called a "politics of the first person." In part, this expresses a rejection of representative politics of any stripe. They are equally antagonistic toward capitalist and state-socialist economic systems, and they reject the structural hierarchy and ideological dogmatism they see as inherent in old-leftist strategies for social change that call for an intellectual vanguard to lead "the people" in revolution. As a group in 1981 put it in their "Theses on the Autonomous Movement":

We fight for ourselves, others fight for themselves, and together we are stronger. We are not leading any representative struggle. It works through personal participationpolitics of the first person. We are not fighting for any ideology, not for the proletariat or for "the people," but for a self-determined life, well knowing that we can only be free when all others are free as well! (Anonymous 1981)

On a deeper level, though, a politics of the first person refers to a commitment to a prefigurative praxis that aligns means and ends, expressed in the slogan der Weg ist dos Ziel, or "the way is the goal." If the way is the goal, and autonomy is their central value, then being autonomous is both the end they seek and the means by which they work to accomplish it. In practice this means that both among themselves and in their interactions with the rest of society they strive to create practices and structures in which they not only refuse to be subservient to others, but also refuse to dominate others. It is this prefigurative principle that underlies their experimentation with non-hierarchical collectivist forms of organization, and makes the scene a critical factor in the movement's development.

The Autonomen first became visible in the mid to late 1970 s as a militant faction within the antinuclear and squatters movements. The importance of militancy, however, reaches far beyond the question of the use of violence as a tactic. In autonomous politics, militancy additionally signifies a radically oppositional standpoint-a refusal to be co-opted or to let one's behavior be dictated by the laws and norms of the dominant society. With the rise of the squatter's movement in 1980 in many larger European cities, the Autonomen became part of a growing alternative scene, characterized by a local infrastructure of bars, cinemas, info shops, book stores, squatted cultural and youth centers, living projects, and media groups. In the 1980 s a potent Autonomen identity began to emerge, containing the following core elements: a dual emphasis on selfdetermination and collective responsibility, an antiauthoritarian leftist political orientation, the devaluation of paid work, a distinctive clothing style, and preferences for punk and "hardcore" music, collective living, non-hierarchical organization, and participatory democratic decision making."

6 While this is a good general description of the movement identity in Germany. it should not be taken as either complete or conclusive, as one distinctive feature of the
The Scene in Berlin

With a population of 3.3 million, Berlin hosts the largest concentration of radical leftists in Germany and also has the largest and most active autonomous scene. The four most common access points for tapping into the information channels of the scene and keeping abreast of leftist politics in Berlin are the streets, scene publications, Indymedia, and scene locales.

As in most German university towns and larger cities, to find out what is "really" going on in Berlin, one does not read the newspapers, one reads the streets. Those arriving in Berlin for the first time, even if they do not know a single person, can find entry into the political scene simply by reading the posters and graffiti that cover the building walls, overpasses, and telephone poles all over town. Posters especially convey all kinds of political information-about protest actions, meetings, informational events, the formation of new groups, and social events like street festivals, parties, and concerts.

As second source of this information are movement newspapers like the Interim or a monthly calendar called Stressfaktor. The Interim is a participatory biweekly newsletter, which has a strong focus on Berlin, but is available and read nationwide. Since its founding in 1988 it has been the most important national discussion forum for the autonomous movement. The Stressfaktor is a monthly events calendar specifically targeted at the radical leftist scene in Berlin. It is available on-line and is also distributed gratis in hard copy at scene locations throughout the city. It includes a calendar of leftist events and actions, a list of standing dates with the addresses of relevant scene locations (numbering one hundred and forty-four at last count, including fourteen leftist bookstores/ "infoshops"), and a "Vokü-Fahrplan," which lists all of the places where one can find "Vokü" (Volkxküche, or people's kitchen) each night.

As a means of social and informational integration into the movement, the Vokü is itself an important scene institution. A number of scene bars and living projects open their doors once or twice a week to offer a hot homemade meal for $€ 2-3$ a plate (roughly $\$ 3$ or $\$ 4$ ). At this writing, the Stressfaktor lists an average of eleven different scene locations offering Vokü on any given weeknight; five on Fridays and Saturdays. Vokü offers activists on a budget an affordable opportunity to eat out in a way that corresponds to their political principles (generally: organic, vegan or vegetarian, inexpensive, and social), and in a place where they can "come as they are" and socialize with other radical

autonomous movement is its tendency to resist the development of any stable collective identity or ideology (Leach forthcoming).

7 The scenes relevant for the autonomous movement are variably described as "radical leftist," "leftist," "autonomous," or "alternative." Most people involved in scenes refer to them simply as "the scene" without any modifier.

8 Aside from books infoshops sell a whole range of movement-made political goods, including pamplets, posters, $t$-shirts, videos, records, patches, and buttons. 
leftists. As a way of drawing people from the scene into the movement, many venues schedule Vokü right before a more political activity such as: a plenary meeting or panel discussion.

A third point of access in Berlin for information about the autonomous movement and leftist politics in general is the website of the German Independent Media Center (IMC). Intended as a grassroots corrective to the mainstream bias of commercial media, "Indymedia's" participatory, interactive concept of activist-reporting gives activists and others a chance to read firsthand accounts of protest events from the perspective of the participants themselves, as well as position papers, announcements, and calls to action. The sites are also structured for readers to contribute to a running commentary in response to each article. There is a filter that screens out postings with overtly racist, sexist, and fascist content, but otherwise everything gets posted, even if it ends up in the "postings not offering any new content" section. Beyond just disseminating information, this interactive structure pulls the reader into the fray, making it easy to get involved.

Whatever the point of departure, however, all roads to leftist political engagement eventually run through the scene itself. With information gathered from the streets, Interim, Stressfaktor, or Indymedia, people might first go to an action or festival where they would meet others who might then take them to a scene location-maybe to attend a political meeting, have an affordable drink or meal, pick up flyers or buy a book, go to a movie, see a panel discussion, or maybe find a locally produced video of last month's protest action. Or people may go on their own directly to an event in one of the scene locales. Once there, they soon realize that not only are they tapped into a social network in a safe space with like-minded people and similar tastes, but they also have stable access in these places to all kinds of current political information via the posters, flyers, brochures, pamphlets, and movement periodicals that are regularly laid out there. One could stay informed without hanging out at scene locations, but it is more difficult, and it is almost impossible to stay involved without having some contact with the scene.

The scene in Berlin is geographically concentrated, though as we will see not as concentrated as the Hamburg scene. Scene establishments can be found in almost any part of town, but they are most visible and concentrated in the districts of Kreuzberg, Prenzelauer Berg, Mitte, and Friedrichshain. That the latter three districts are in what was formerly East Berlin is no coincidence.

9 See http://germany.mdymedia.org/. Since the first IMC was formed in Seattle in preparation for the protests against the WTO in 1999, one hundred and seventy-seven IMC collectives have been founded around the world, one hundred and sixteen of them outside of the US. Each autonomous collective must agree with the general IMC concept and structure. The mission statement on the German site reads (translated) "Indymedia is an international network of media initiatives and activists for independent and noncommercial news coverage from below-on location and worldwide. It sees itself as part of the worldwide resistance against capitalist globalization."
Kreuzberg has been the heart of the scene for several decades, but when the wall came down, the Autonomen and others took advantage of the situation and squatted a large number of empty houses in East Berlin. Though most squatters were eventually forced to sign leases, the projects that were founded in these squats nevertheless successfully extended a strong radical leftist presence into a much wider area. There is also a territorial possessiveness that develops in the parts of town where the scene is most entrenched. One sees this reflected in action campaigns mounted to defend individual "leftist structures" against evictions and rent increases, often coordinated by the "Pi-rat" (Projects and Initiatives Council). Identification with particular parts of town is also manifested in the physical defense of the territory itself against incursions by opposing groups, such as the Autonomen's efforts to keep Kreuzberg a "Nazifree zone."

\section{The Hamburg Scene}

Hamburg is Germany's second largest city with a population of about 1.8 million people. Despite extensive damage in WWII its densely populated core still contains large tracts of old multistory buildings. Urban fight during the 1960s and 1970s and the poor conditions in many of these houses made spacious and relatively cheap inner-city housing in Hamburg accessible to the less privileged - especially immigrants and students. Here, as in other German cities, the availability of cheap housing that allows low-income young people to live together in shared apartments (Wohngemeinschaften) was the first building block for Hamburg s scene. In the 1980 s these conditions existed in the neighborhood known as the "Schanzenviertel," and since that time this part of town has been the center of the autonomous scene in Hamburg. Citing the scene as an indicator of the success of ten years of struggle against urban renewal projects in this part of town, one "old Autonomer" comments:

Moreover, there is the veritable service network of the scene, from bars, cafes, book and record stores, and taxi collectives to clothing stores and several social facilities, that guarantees bread and wages to activists in the area. On top of that there's an array of implemented living projects and the Rote Flora, the autonomous community: center that's been squatted and self-managed without paid staff from November 1989 until today. (Blechschmidt 1998: 83-4)

The visible epicenter of the Hamburg scene is still the "Rote Flora,"located on the main shopping street in the Schanzenviertel. The building offers space for a range of groups and activities: political groups meet there, there are practice rooms for local musicians, an archive of movement documents, a motorcycle repair shop, and a silk screen print shop, and several days a week the bar offers Vokü. During the 1990s, the Flora was the default location for larger political meetings, and it still puts out the local autonomous movement newspaper. For 
the majority of its visitors, however, the Rote Flora is primarily a venue that hosts concerts and parties almost every night, with various styles of music that often have broad appeal but are not culturally mainstream.

Most of Hamburg's scene infrastructure is located in the immediate vicinity of the Rote Flora. The "Schwarzmarkt," a volunteer-run autonomous infoshop located in a formerly squatted house, serves as the main distribution point for political fiyers, brochures, books and posters. More political in character than the Rote Flora, it is frequented almost exclusively by committed movement activists. A non-profit bar in the same building attracts a much wider public and reaches out especially into the alternative gay subculture. Also close by is the "B5" (shorthand for its location in the Brigittenstraße 5) another community center in a formerly squatted building that houses a community-run cafél bar, a community kitchen, and a non-profit alternative cinema. With a varied daily program, the B5 attracts people from a range of cultural and political backgrounds, from cultural hedonists to anarchists. Maoists, and Stalinists. It functions as well as a bridge to a number of radical leftist Turkish and Kurdish organizations that hold their weekly meetings there. Other scene locations in the immediate vicinity of the Rote Flora include an alternative bookshop, an anarchist center, an alternative radio station, alternative projects, and a number of bars that have been founded by former movement activists or fellow travelers.

Hamburg's autonomous scene is smaller and geographically more centralized than Berlin's. As in Berlin, the scene's boundaries are also visibly marked by political posters, which are abundant on walls, fences, and any other suitable surfaces in certain areas of the city but virtually non-existent everywhere else. These areas coincide with the neighborhoods that contain the bars and venues of the autonomous and/or alternative scene, and are at the same time the neighborhoods in which most movement activists live. Certainly, people who identify with the scene also live in other neighborhoods in Hamburg but the concentration is nowhere near as dense as it is in and around the Schanzenviertel.

To further illustrate the character and scope of the Berlin and Hamburg scenes, we have collected data from the online leftist calendars for the two cities, Stressfaktor and Bewegungsmelder, for the months of April, July, and October in each of three years, 2003, 2005, and 2007. Table 10.1 shows the number and type of various kinds of events per month. We see a relatively stable number of demonstrations, and a sizable number of political and cultural events announced each month. The total number of events is always significantly higher in Berlin, reflecting in part the larger size of the leftist scene there, but also the more established readership of the Stressfaktor.

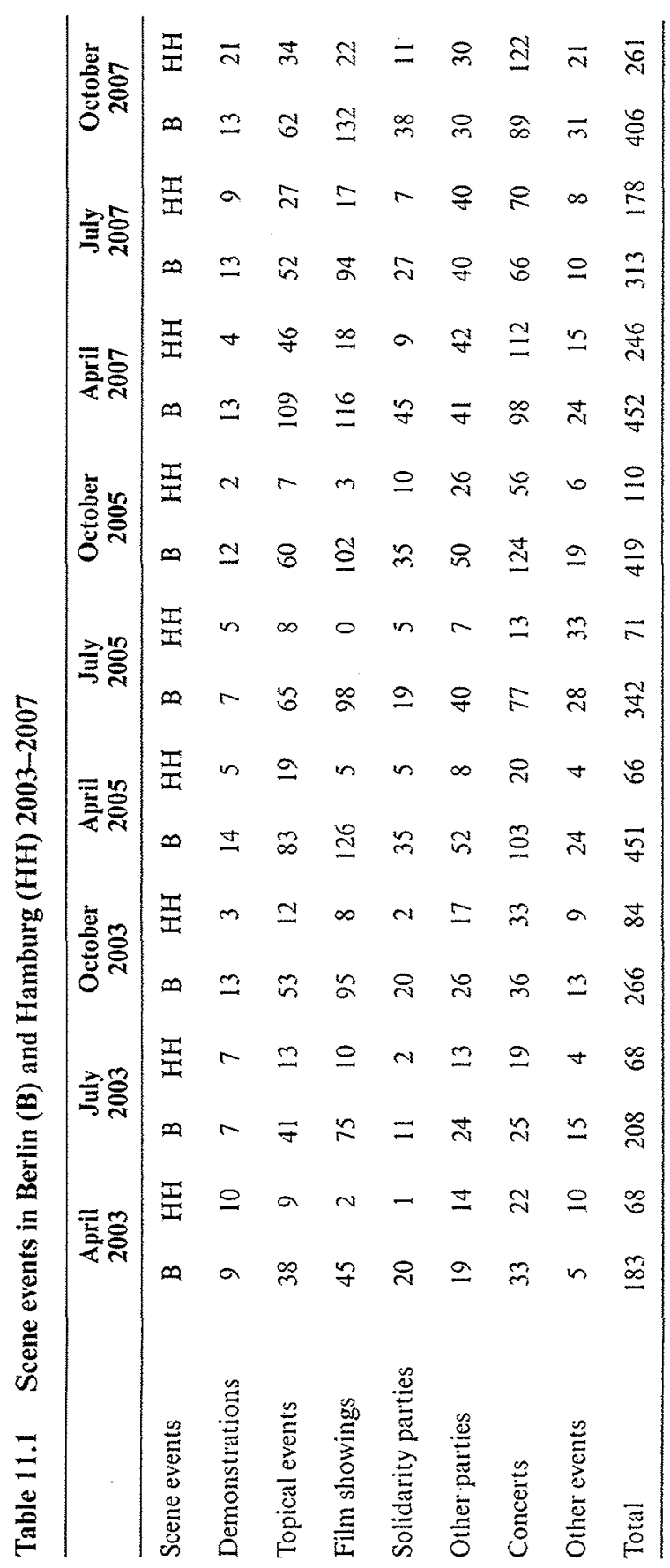


In Figure 11.1 we have collapsed this data into categories of cultural and political events for each city. ${ }^{10}$ The figure shows that for the most part cultural and political activities followed a parallel pattern. The data therefore show fluctuations in the level of overall scene activity but no shift in focus over time from political to cultural or vice versa. The peak in April 2005 in Berlin was caused mainly by the mobilization around the annual demonstration on May 1 (Rucht 2003), which that year involved a concerted attempt to "re-politicize" the event. The peak in April 2007 that is visible in both cities reflects the big mobilization push leading up to the G8 meetings held in June in Heiligendamm.

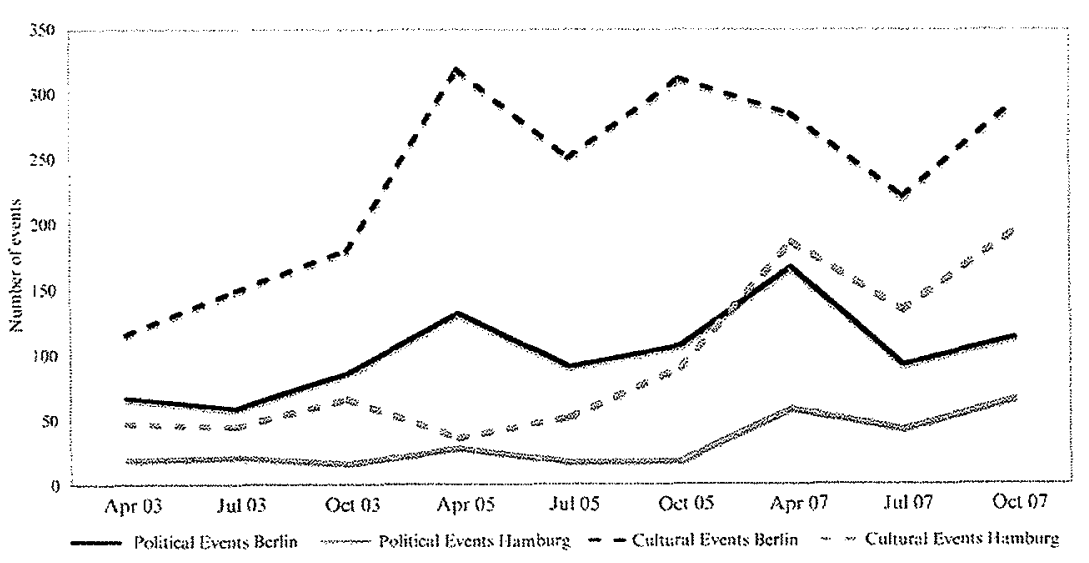

Figure 11.1 Cultural and political activities in the Berlin and Hamburg scenes

\section{Scenes and Social Movements}

Not all movements require or develop scenes, which raises the question: Under what conditions would we expect movements to become attached to scenes? Based on the Autonomen, we would expect scenes to develop in new social movements whose political ideals are intimately bound up with their day-today personal behaviors, and for whom defending, creating and/or promoting a marginalized, repressed, or countercultural way of life is an essential aspect of their political praxis. Others have referred to movements in this category as

10 In the category of political events we included demonstrations, topical events, and solidarity parties/concerts; under cultural events counted films, parties, concerts. and other events. Because solidarity parties serve an explicitly political purpose, we counted them in the political events category. and parties that were not explicitly political as cultural events. "left-libertarian" (della Porta and Rucht 1995), "expressive" (Rucht 1990), and "nonviolent direct action" (Epstein 1991) movements. Specific examples might include the radical wings of the women's, peace, and environmental movements, the lesbian-feminist movement, and the gay movement-at least in the US and Germany-and on the other side of the political spectrum, neo-Nazi, nationalist, and fundamentalist religious movements. Whatever their orientation, countercultural movements striving for a fundamental reorganization of society and trying to live in a way that prefigures their desired social arrangements and subcultural movements seeking to defend and preserve a stigmatized and/or repressed subcultural lifestyle are the most likely to develop a scene. Thus, we offer two general propositions about scene-movement linkages.

1 Scenes are likely to develop around movements that operate according to a prefigurative, value-rational logic and are concerned with creating, promoting, and/or preserving a particular subcultural or countercultural lifestyle.

2 The more a subcultural lifestyle is stigmatized and repressed, the more likely it is to take on a political-orientation characteristic of a movement scene, usually in defense of its right to freely exist, unmolested by the dominant culture.

European autonomous scenes have benefited from a number of structural and historical conditions that facilitated their emergence. Because of their embeddedness in physical space, several factors related to the rise of a widespread squatters' movement are relevant. Primary among them are a legal environment favoring squatters' rights and widespread housing shortages (aided in the German case by reunification, which spurred rampant speculation and ambiguity about who could lay legitimate claim to previously state-owned properties in the East). Also key in the Autonomen case was the existence of an advanced welfare system with unemployment insurance and a universal health-care system in which benefits were not tied to employment status. These combined to guarantee a minimum standard of living, reducing the urgency of finding full-time employment and making it possible for the underemployed and unemployed to engage full-time in radical politics. Also relevant here are the Kindergeld entitlement program (which pays a fixed monthly amount to parents for each child until s/he either finishes college or reaches the age of twentysix), a university system with only nominal tuition fees (by US standards), and government loans that make it possible for a large proportion of students to finance their education without having to find paid employment. Last, more relaxed regulations and/or enforcement about such things as the sale and public consumption of alcohol, the sale of home cooked food, and public film showings make it much easier for groups to subsidize their activities through such mainstays of the scene as Vokü, cocktail hours, and solidarity parties, 
rather than being dependent upon foundation grants. Thus, we suggest the following propositions about scenes and the structural environment.

3 Scenes are more likely to develop where conditions are conducive to squatting and/or where rents are low enough to support non-commercial initiatives.

4 Scenes are more likely to develop in more advanced welfare states which are more conducive to full-time political engagement and where social regulation facilitates independent, socially based fundraising methods.

\section{Scenes and Mobilization}

The most straightforward way in which the scene enhances mobilization is by providing a ready pool of potential recruits. The German Minister of the Interior's Federal Office for the Protection of the Constitution estimates that while there are only about 5,500 Autonomen in the country, the movement has a mobilization potential of closer to 10,000 within the scene (Bundesministerium des Innern 2006). Because a scene offers a sense of community at a low social cost, it attracts more people than the movement does. Subcultural activities in the scene, like concerts and parties, attract people and continuously expose them to the movement's political lifestyle and ideology in a low-pressure context. And while the scene attracts people to the movement, the edgy/dangerous image of the movement also attracts people to the scene. Because engagement in the movement requires a greater commitment and often a willingness to engage in high-risk activity, one advantage of the scene is that it provides a way of "easing into" the movement, with the first step being subcultural identification with the scene. The next step can be left open for a relatively long period of time, but once people begin to feel connected to the scene, they are much more likely to increase their level of commitment, due to the "foot-in-the-door" principle whereby people feel compelled to act in a way that is consistent with an initial (if unintentional) commitment. This means that as long as the scene remains culturally attractive, the movement need do little more to mobilize people for an action than simply to publicize the event within the scene.

5 Movement scenes serve as a gateway to active engagement in the movement-a low-pressure context in which people are exposed to movement norms and then feel drawn to make a greater commitment due to consistency pressures.

The relationship between scene and movement is not always mutually reinforcing, however, as developments in the Hamburg scene illustrate. While concerts and parties at the Rote Flora bring people into contact with the autonomous movement who otherwise would have little interest in its political claims, this function of the scene also challenges the movement to deal with positions and lifestyles that conflict with those claims. A review of the local movement newspaper shows that the relationship between (sub)culture and politics-between scene and movement-in the Rote Flora has always been conflictual, especially since the advent of techno music in the mid-1990s, when the more hedonistic lifestyle of the techno subculture came into conflict with the more ascetic and anti-consumerist ideals of the movement counterculture. Over time, however, the techno subculture has de facto opened up the spectrum of "allowable" lifestyle choices in the movement. On the one hand, this has been positive, as the movement has become accessible to a larger potential constituency, but it has also had negative consequences, as the movement's principles and its everyday radical practices have been diluted.

6 In countercultural movements, tensions between movement and scene are often rooted in the trade-off between openness and purity - between the need to reach a broader public and the danger that this will undermine the movement's adherence to a prefigurative praxis.

Certain spatial and discursive characteristics of scenes may also influence mobilization by structuring the flow of information. In the autonomous movement, the scene tends to be the target audience to which almost all movement communications are addressed. Geographic concentration, as exemplified by the Hamburg scene, amplifies this tendency. The general public is virtually ignored, severely limiting the movement's reach. In Hamburg, this concentration positively affects the movement's ability to mobilize quickly in response to political challenges, because information distributed through the dense network of bars and shops in the scene reaches a large number of likely supporters with little effort. It also fosters a tight-knit cultural matrix in which verbal communication is the primary means of information exchange, with all of the advantages and disadvantages that brings. On the positive side, there is an increased sense of commitment through the development of insider linguistic codes and dense social ties. On the downside, this verbal, self-referential infrastructure makes the movement virtually invisible to those who do not regularly frequent the right bars, parties and events, and who are thus easily cut off from the movement's information flows. Although some of this information is publicly available in the indymedia websites, political posters, and newspapers, it is not likely to be understood by anyone who is not conversant in the scene's vernacular or who does not at least share/understand its underlying assumptions.

Granovetter's (1983) theory of the strength of weak ties may help to unravel these contradictory tendencies. When scenes have a relatively greater number of weak ties with the broader society, they should have more access to the resources, information, and ideas that would enhance mobilization. On the other hand, effective mobilization (measured as successful turnout of those asked) depends most directly on the density of the network-on the existence of strong ties. 
So the movement's vitality over time should depend on there being a sufficient number of weak ties between groups within the scene and between members of the scene and the rest of society, but the mobilization potential of the movement at any given time will depend on the overall density of the scene's network

7 Due to the greater density of social ties, geographically concentrated scenes should have more success mobilizing within the scene, but they are also likely to generate more insular norms of interaction and discourse, limiting their scope of influence.

8 The tendency toward insularity may be offset to the degree that weak ties between local scenes in different locations facilitate exposure to a broader population and increase access to resources, diverse ideas, and information.

\section{Collective Identity and the Politics of Everyday Life}

Scenes play a central role in the construction and maintenance of alternative identities, lifestyles, and modes of interaction. An important connotation of the Autonomen principle of a "politics of the first person" is that activists should organize around their personal experiences and interests while simultaneously working to minimize the degree to which their own behaviors contribute to the oppression of others (Leach 2006). In the autonomous movement, the scene facilitates this process of integrating the personal and the political by providing the space in which to (a) construct an oppositional ideology and collective identity, and (b) create and implement associational forms and norms of interaction that embody their anti-authoritarian values. Collective movement identities are not only constructed during the meetings and actions of social movement organizations, but also through the performance and negotiation of what it means to be a member of the movement in their everyday lives. These processes can take place in any social space where it is relatively safe to be different. For movements that generate scenes, constructing a collective identity is about more than self-expression or affirmation; it is itself a component of the change being sought, a form of subjectivity understood to prefigure the kind of world for which they are fighting. For these movements, the scene is the primary location for identity work.

Parallel to the construction of new identities are the processes by which such movements construct alternative norms and forms of organization as a part of their strategy for social change. For the Autonomen, whose ideal is a "dominance-free society" (herrschaftslose Gesellschaft), the scene is a cultural laboratory for experimenting with non-hierarchical ways of structuring daily life. They seek spaces that are free of any pre-existing rules that would inhibit their efforts, and then work to create sustainable non-hierarchical forms of organization characterized by radically democratic decision-making processes and non-oppressive modes of social interaction. While it is not true across the board, scene locales in Berlin and Hamburg are generally organized as collectives that operate either by consensus or some other form of direct democracy (see della Porta, Chapter 8 in this volume). This non-hierarchical ideal is evident in every kind of movement group and gathering, from the open plenaries, affinity groups, regional delegate meetings, national conferences, and action camps of the movement itself, to the bars, info shops, theaters, media projects, squats, finance collectives, and community and youth centers of the scene, to transmovement collectives that provide cooking, training, legal aid, and street-medic services for activists, and those offering support for newly forming collectives.

However, this close integration of politics and everyday practices can also generate deep conflicts about how best to implement the movement's principles, for example over what constitutes sexist behavior, or criticisms of consumerist lifestyle practices in the scene. Alongside traditional struggles over organization and decision making, these lifestyle conflicts prominently influence the viability of the movement.

9 In movements that stress the integration of politics and everyday life processes related to identity and cultural construction are likely to be centered in the scene, rather than in official movement organizations and activities, and conflicts between movement and scene are likely to be focused on these processes.

\section{Scenes and Movement Longevity}

The final issue in which scenes seem to be deeply implicated has to do with the movement's ability to sustain itself over time and/or rebound after periods of inactivity. In a study of three German locales where movement activity was particularly robust, Roth (1994) found that social movements avoided becoming institutionalized by becoming institutionalized as movements. That is, they sustained a heightened level of extraparliamentary activity, because extraparliamentary engagement had become the normative form of interest representation. Roth attributes this to "stable local movement networks" in each place, consisting of "communications centers, media, and alternative living forms and projects" (Roth 1994: 413). These networks facilitate sustained mobilization, cushion against defeat, and encourage self-reflection and learning.

Based on Roth's study and others, we would posit three general ways in which scenes are likely to contribute to movement longevity. The first is as "abeyance structures" for the whole movement during periods of low activity. As others have pointed out, free spaces can provide a way for activists to maintain their movement identity, when it has once again become stigmatized or marginalized without the strength of the movement behind it (Taylor 1989; Taylor and Whittier 1992, 1995; Taylor and Rupp 1993). Because the autonomous movement in Germany has never had a sustained period of inactivity, it is 
difficult to say to what degree the scene has contributed in this way, but it is clear that the scene has continued to flourish even when the movement has not been highly active.

Second, generalizing from the Hamburg and Berlin cases, we suggest that scenes serve as a kind of living archive that helps preserve movement identity and cultural practices. Tactical innovations, organizational forms, decision-making practices, strategic lessons, movement history, symbols, frames, theoretical analyses, and movement identities are all preserved and transmitted to subsequent waves of activists through the scene. In a movement with no central organization and little if any formal organization, this is an especially important (and difficult) task. Activists themselves have documented and preserved the movement's history and ideology through a variety of media, including selfpublished books (Geronimo 1997, 2002; HSK 13 1999; AG Grauwacke 2003; Haunss 2004), documentations of important protest events, and self-managed movement archives such as the Papier Tiger in Berlin, the archives at the Rote Flora, and many others. Websites like the one put together by AG Grauwacke" also have worked to make movement documents more accessible and encourage participation in writing the movement's history.

Third, scenes may serve as "retreat structures"-to coin a term-for individual activists during phases of high activity, a function not typically attributed to abeyance structures. In the autonomous movement this has been especially important in response to repression or as activists get older and the requirements and demands of constant mobilization lead to burn out. In both cases, they always have the option to use the scene as "a retreat place" (Rückzugsort) where they can stay in touch with the movement but reduce the overall amount of time and energy they invest. leaving them available for later mobilizations. This effect has been most obvious when central movement institutions have come under threat. For example, when underground movement newspapers have been targeted by state repression, the subsequent solidarity campaigns often involved unusual numbers of older activists who often had not been active in the movement for some time. We therefore offer the following proposition, recognizing that the Autonomen case is only suggestive.

10 Scenes support longevity in different ways during different phases of the movement, providing individuals with a means of "laying low" and/or recharging during periods of peak activity, and preserving movement identities and culture during periods of decline.

11 http://autox.nadir.org/archiv/auto/index.html.

\section{Conclusion: Scenes and Social Movement Research}

Based on our analysis of two scenes attached to the German autonomous movement, we have argued that scenes can play a vital role in movement processes related to mobilization, the construction and maintenance of collective identities, practices and organizational forms, and movement longevity. For value-rational movements, whose lifestyles are severely marginalized or whose interests stand in opposition to those of dominant elites, acquiring support from mainstream institutions may require too great a compromise in their interests or ideological principles. Such movements will more likely rely on scenes to facilitate mobilization, sustain commitment, connect politics and everyday life, construct alternative collective identities, and preserve their traditions, innovations, and ideologies over time-even if these activities may hamper their chances to advance their political goals or attract support

We have offered our propositions as a first step in thinking about scenes as a different type of free-space configuration. Based on the Berlin and Hamburg scenes, we have distilled several basic relationships that are directly implicated in movement dynamics, but are not captured by current theorizing about free spaces. Still, there are a number of important topics that remain to be considered, such as the relationship between state repression and the vitality of movement scenes, the role of subcultural scenes that are not attached to movements and the conditions under which they become political, and the impact of countermovements on movement scenes. In Germany, for example, there is a long-standing conflict between Autonomen and neo-Nazi groups including violent confrontations and attempts to shut down each others' scene locations, but space limitations have not allowed us to pursue this topic.

In choosing new cases to refine the scenes concept, two questions should be central in guiding future inquiry. First, we need to understand more about the conditions under which scenes take root and thrive. For example, even though the collectivist-democratic structure used in the German autonomous scene can in part be traced back to the US anti-nuclear movement in the mid-1970s, and even though there have been a few examples of countercultural movements scenes in the US, like the one that developed in the Haight-Ashbury district in San Francisco, neither the structure nor the scene has proved sustainable in the US context. In contrast, both have taken root in much of Western Europe and have prospered in Germany for nearly three decades now, to the point of becoming taken-for-granted features of extraparliamentary politics (Leach 2006). How can we explain these patterns of diffusion?

Second, for comparisons, it would be useful to know more about the negative effects scenes may have on a movement. We have argued that movement scenes play an important role in collective identity processes by providing an infrastructure for bridging politics and everyday life. The effectiveness of scenes as mobilization pools, movement abeyance structures, and individual retreat structures lays in the fact that they act as a cultural buffer, blurring 
the boundaries of the movement and making it easy for people to move in and out of active engagement. But their role as lifestyle communities can also negatively affect a movement by alienating people with more mainstream lifestyles. In his comparative study of collective identity processes, for example, Haunss (2004) has shown that the second German gay movement was not only founded in explicit opposition to the gay scene, but also coexisted in a conflictual relationship with it. Also, the geographical concentration of scenes in a few neighborhoods can lead activists to be ignorant of or even act condescendingly toward other neighborhoods, thereby limiting the movement's reach.

As a community of meaning in which oppositional ideologies and alternative cultural forms are constructed and performed, scenes occupy an intermediate location between the movement and broader political contexts and serve as a cultural lens that mediates the way political opportunities are interpreted at the local level. As such, the performances that occur in scenes may be thought of as bridging the gap between cultural and structural approaches to movement dynamics (Goodwin and Jasper 2004). In its duality as both a social network and a network of spatial settings, a scene is a cultural laboratory where macrolevel opportunities are discussed and evaluated in terms of personal politics and political ideals. The influence these processes have on movement trajectories points to the pivotal role of social movement scenes.

\section{Works Cited}

Abbot, Andrew. 1995. "Sequence Analysis: New Methods for Old Ideas" Anmual Review of Sociology 21:93-113.

Ableson, Robert P. 1981. "The Psychological Status of the Script Concept." American Psychologist. 36: 715-29.

AG Grauwacke. 2003. Autonome in Bewegung: aus den ersien 23 Jahren. Berlin: Assoziation A.

Agrikolianski, Eric, and Dominique Cardon, 2005, "Un programme en débats: forum, formes et formats." Pp. 45-74, in Radiographie du mouvement altermondialiste, Eric Agrikolianski and Isabell Sommier, eds. Paris: La Dispute.

Alexander, Jeffrey. 1990. "Analytic Debates: Understanding the Autonomy of Culture." Pp. 1-27 in Culture and Society: Contemporary Debates, Jeffrey Alexander and Steven Seidman, eds. New York: Cambridge University Press.

Alexander, Jeffrey. 2006. "Cultural Pragmatics: Social Performance between Ritual and Strategy." Pp. 29-90 in Social Perfomance: Symbolic Action, Cultural Pragmatics and Ritual, Jeffrey Alexander, Bernhard Giesen, and Jason L. Mast, eds. New York: Cambridge University Press.

Alexander, Jeffrey C., and Jason L. Mast 2006. "Introduction: Symbolic Action In Theory and Practice: The Cultural Pragmantics of Symbolic Action." Pp. 1-28 in Social Performance, Jeffrey C. Alexander, Bernhard Giesen, and Jason L. Mast, eds. New York: Cambridge University Press.

Alexander, Jeffery, Bernhard Giesen, and Jason L. Mast. 2006. Social Performance: Symbolic Action, Cultural Pragmatics and Ritual. New York: Cambridge.

Almond, Gabriel, and Sidney Verba. 1963. The Civic Culture. Princeton, NJ: Princeton University Press.

1989. The Civic Culture Revisited. Newbury Park, CA: Sage.

Alsop, Joseph, and Robert Kintner. 1941. "Ways and Means of the Opposition." Wushington Post (May 28): 11.

Amenta, Edwin, and Michael P. Young. 1999. "Making an Impact: Conceptual and Methodological Implications of the Collective Goods Criterion." Pp. 22-41 in How: Movements Matter. Theoretical and Comparative Studies on the Consequences of Social Movements, Marco Giugni, Doug McAdam, and Charles Tilly, eds. Minneapolis, MN: University of Minnesota Press.

Amenta, Edwin, Kathleen Dunleavy, and Mary Bernstein. 1994. "Stolen Thunder: Huey Long's Share our Wealth, Political Mediation, and the Second New Deal." American Sociological Review 59: 678-702. 